\title{
Desain Mesin Pemotong Rumput Tipe Rotari Dengan Mesin Penggerak Motor Listrik
}

\author{
Kahar $^{1}$ \\ ${ }^{1}$ Teknik Pertanian STIPER KutaiTimur \\ Email: kahar@stiperkutim.ac.id
}

\begin{abstract}
Rotary-type lawn mower is a mower that cuts based on blade collision (impact) of grass free cutting with a high speed rotation. Research was conducted on March up to June 2017. Research aims to design of Rotary-type lawn mower - with Electric Motor Propulsion, determine the efficiency and power requirements of tool by experimental methods is to test a tool that has been designed in connection with structural and functional design and analyze the obtained data of tools test to determine the efficiency and power requirements. Tool parts of rotary-type lawn mower was created consisting of the frame, deck, blade holder, blade, motor and battery as a current source of propulsion. The theoretical field capacity of rotary-type lawn mower 0,0186 ha/hour, The Effective field capacity of rotary-type lawn mower 0,013 ha/hour ${ }^{1}$. Field efficiency of rotary-type lawn mower average $70,4 \%$ and power required of rotary-type lawn mower was 179,67 Watts.
\end{abstract}

Keywords: Design, Lawn Mower, Rotary, Efficiency.

\begin{abstract}
ABSTRAK
Mesin pemotong rumput tipe rotari adalah pemotong rumput yang memotong berdasarkan benturan (impact) pisau terhadap rumput (free cutting) dengan kecepatan putaran tinggi. Penelitian ini dilaksanakan pada bulan Maret sampai Juli 2017. Tujuan penelitian adalah membuat desain mesin pemotong rumput tipe rotari dengan motor penggerak motor listrik serta mengetahui efisiensi dan kebutuhan daya alat dengan metode eksperimen yaitu melakukan uji coba alat yang telah di desain sehubungan dengan rancangan structural dan rancangan funsional dan menganalisis data uji coba alat yang diperoleh untuk mengetahui efisiensi dan kebutuhan daya alat.

Bagian alat mesin pemotong rumput tipe rotari yang dibuat terdiri dari rangka, deck, dudukan mata pisau, mata pisau, motor penggerak, dan baterai sebagai sumber arus tenaga penggerak. Kapasitas kerja lapang teoritis mesin pemotong rumput tipe rotari sebesar $0,0186 \mathrm{ha} / \mathrm{jam}$, kapasitas kerja lapang efektif rata-rata mesin pemotong rumput tipe rotari sebesar $0,0131 \mathrm{ha} / \mathrm{jam}$, Efisiensi kerja lapang rata-rata mesin pemotong rumput tipe rotari sebesar $70,4 \%$, dan daya yang dibutuhkan motor penggerak mesin pemotong rumput tipe rotari adalah sebesar 179,67 Watt.
\end{abstract}

Kata kunci: Desain, Mesin Pemotong Rumput, Rotari, efisiensi.

\section{Pendahuluan}

Penggunaan rumput sebagai tanaman lanskap dapat meningkatkan kualitas estetika bangunan dan lingkungan secara keseluruhan. Untuk keperluan ini dibutuhkan rumput yang memenuhi kualitas visual seperti kerapatan tekstur, keseragaman, warna, sifat pertumbuhan serta kehalusan, dan kualitas fungsional seperti kelenturan, kepegasan, kesegaran, perakaran dan daya pemulihan. Kualitas ini dapat diperoleh dengan pengelolaan dan pemeliharaan rumput yang tepat seperti peremajaan dan pemotongan. Pemotongan rumput merupakan salah satu kegiatan penting dalam pemeliharaan rumput lanskap, untuk mendapatkan hamparan rumput yang seragam, rapat dan merata. Pemotongan dilakukan dengan menggunakan alat atau mesin pemotong rumput (mower) baik yang manual maupun bermesin. Salah satu mesin pemotong yang banyak digunakan 
ISSN 2354-7251 (print)

untuk memotong rumput dilapangan atau taman adalah mesin pemotong rumput tipe rotari (Kumurur, 1998).

Mesin pemotong rumput tipe rotari adalah pemotong rumput yang memotong berdasarkan benturan (impak) pisau terhadap rumput (free cutting) dengan kecepatan putaran tinggi. Pada mesin pemotong ini kecepatan putar dan ketajaman pisau akan sangat berpengaruh terhadap kualitas hasil pemotongan. Hasil pemotongan mesin pemotong rumput tipe rotari tidak sebaik mesin pemotong rumput tipe menggunting (reel mower), namun demikian mesin pemotong rumput tipe rotari dapat memberikan hasil potong yang dapat diterima pada hamper semua jenis kondisi areal potong, dapat diperlakukan sedikit lebih kasar dengan masih mempertahankan hasil potongnya, serta tidak serumit dan semahal mesin pemotong rumput tipe reel (Suharyatun, 2001).

Mesin pemotong rumput yang banyak digunakan untuk memotong rumput dilapangan olahraga atau taman adalah mesin pemotong rumput tipe rotari dengan menggunakan motor bensin sebagai motor penggerak. Okafor (2013) Mesin pemotong rumput rotari menggunakan bahan bakar bensin dengan sistem pembakaran internal dan umumnya bergerak secara manual dengan mesin hanya memutar pisau pemotong. Madhav (2015) mesin pemotong rumput rotari mengunakan bahan bakar dan memerlukan biaya mahal, menimbulkan kebisingan, konsumsi bahan bakar bensin tinggi dan menimbulkan kelelahan bagi operator dalam pengoperasian dengan jangka waktu lama. Pada mesin pemotong rumput dengan menggunakan motor bensin tidak dilengkapi dengan alat kontrol seperti sakelar yang akan mematikan dan memperlambat atau mempercepat putaran motor bensin.

Torsi pemotongan dan hasil pemotongan merupakan informasi penting dalam mendesain mesin pemotong rumput tipe rotari. Berdasarkan hasil penelitian yang pernah dilakukan, parameter-parameter utama pisau pemotong rumput tipe rotari yang berpengaruh terhadap efisiensi gaya dan torsi pemotongan rumput adalah kecepatan maju pemotongan, jari-jari pemotongan, jumlah dan pemasangan mata pisau. Untuk mendapatkan pemotongan yang efisien dibutuhkan kecepatan putar di atas kecepatan kritis yaitu 25 - 30 m.s-1 (Dogherty, 1991).

Sampai saat ini sebagian besar mesin pemotong rumput tipe rotari yang digunakan di Indonesia khususnya di Kabupaten Kutai Timur adalah mesin-mesin impor. Dengan semakin meluasnya penggunaan mesin pemotong rumput ini, akan sangat menguntungkan jika mesin ini diproduksi di dalam negeri sendiri. Oleh karena itu studi dan penelitian yang mengarah pada kemungkinan menghasilkan mesin pemotong rumput tipe rotari merupakan satu hal yang cukup penting dilakukan. 


\section{Metodologi Penelitian}

Penelitian ini dilaksanakan dari bulan Maret sampai Mei 2017. Pembuatan alat uji dilaksanakan di Laboraturium Mesin dan Energi Pertanian Jurusan Teknik Pertanian STIPER Kutai Timur. Tempat pengujian dilaksanakan di lapangan Kampus STIPER Kutai Timur Sangatta.

Bahan yang digunakan dalam pembuatan prototipe mesin pemotong rumput tipe rotari adalah Plat besi dengan tebal $2 \mathrm{~mm}, 3 \mathrm{~mm}$, dan $5 \mathrm{~mm}$, Pipa besi medium dengan berdiameter 0.5 inch dan 0.75 inch, Kawat besi dengan diameter $4 \mathrm{~mm}$, Motor listrik $1 \mathrm{hp}$, satu fase dan dua pool dengan putaran 2800 rpm.

Bahan yang digunakan dalam pengujian prototipe mesin pemotong rumput tipe rotari adalah Rumput yang ditanam secara springging (mengambil stolon / batang horizontal yang tumbuh kesamping dari nursery yang ditanam dengan cara penyebaran dan dilakukan rolling) pada luasan lahan yang sudah disediakan.

Peralatan yang digunakan dalam pembuatan desain mesin pemotong rumput tipe rotari adalah Gerinda yang digunakan untuk memotong dan mengikis besi, Las listrik digunakan untuk mengelas antar besi, Bor besi dugunakan untuk mengebor besi, Mesin pembengkok digunakan untuk membengkokkan besi, Alat kerja bangku dan tools pendukung lainnya.

Peralatan yang digunakan dalam pengujian mesin pemotong rumput tipe rotari adalah Patok yang digunakan sebagai tanda dalam membuat petakan tanah, Pita ukur (tape) yang digunakan untuk mengukur luasan tanah dan lebar pemotongan, Stop watch digunakan mengukur untuk kecepatan maju, waktu total pemotongan, waktu pembuangan rumput yang tertampung dalam penampung dan waktu belok, Clamp meter digunakan untuk mengukur konsumsi arus dan tegangan pada uji prototipe mesin pemotong rumput tipe rotary, Kamera digital digunakan untuk merekam gambar yang diperlukan selama pengujian, Multimeter digital untuk mengukur dan sebagai penentu nilai tahanan atau voltase

Metode yang digunakan dalam penelitian ini adalah metode analisis data eksperimen. Data-data yang diperoleh melalui pengujian alat akan dianalisis dengan menggunakan rumus-rumus empiris yang mendukung proses pengolahan data

Prototipe pemotong rumput tipe rotari dirancang dan dibuat, selanjutnya diuji unjuk kerja dan kebutuhan tenaganya pada pemotong rumput dilahan percobaan. Tahapan kegiatan penelitian dilakukan seperti pada gambar 1 . 
Penelitian inii terdiri dari tiga kegiatan yaitu pembuatan prototipe, pengujian lapang dan pengolahan data.

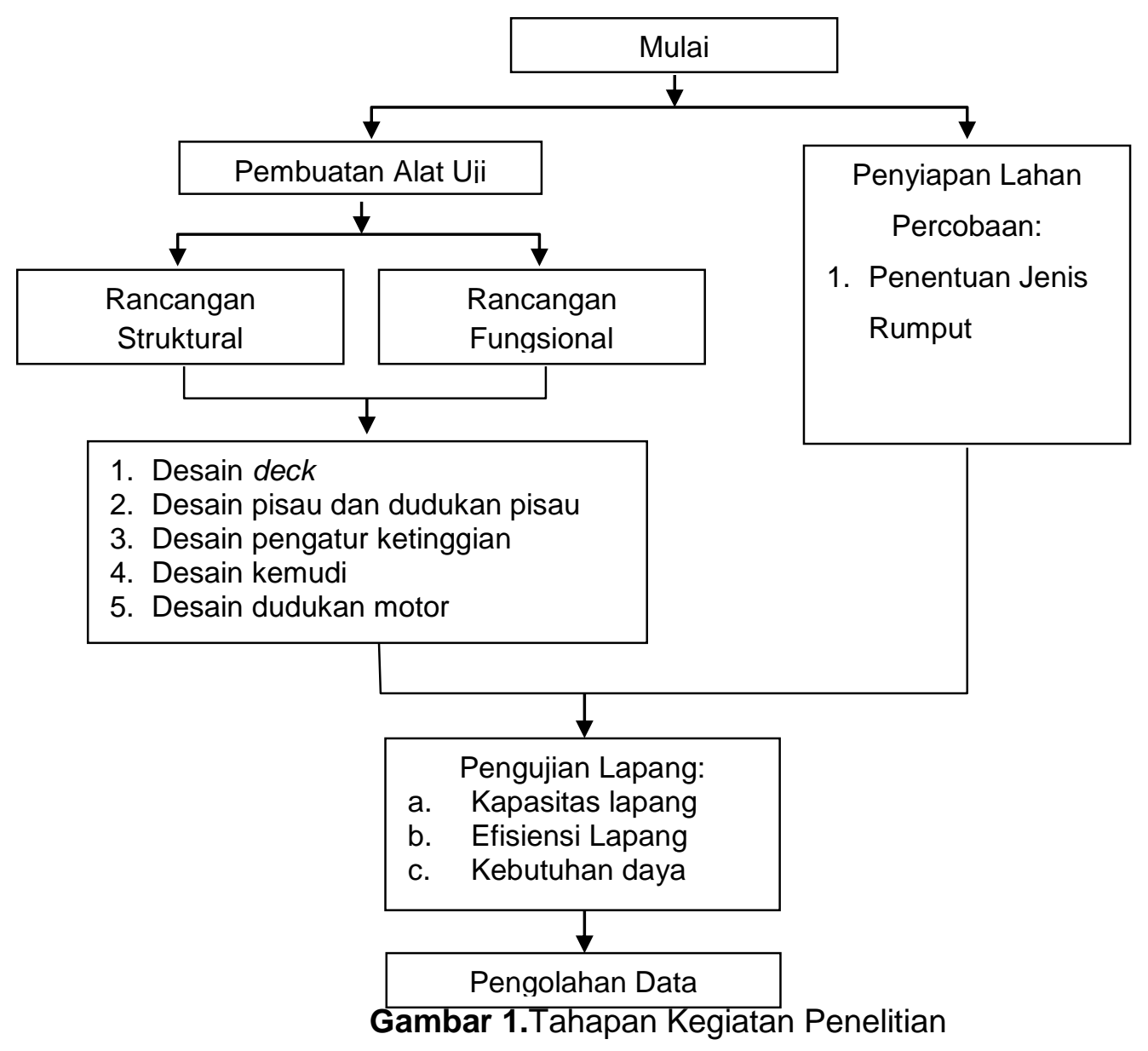

\section{Hasil dan Pembahasan}

\section{Prototipe Mesin Pemotong Rumput Tipe Rotari}

Mesin potong rumput tipe rotari mempunyai dimensi $80 \mathrm{~cm} \times 60 \mathrm{~cm} \times 75 \mathrm{~cm}$. Mesin pemotong rumput ini di operasikan dengan cara didorong oleh tenaga manusia. Kecpatan putar Pisau menggunakan tenaga motor listrik dengan daya $1 \mathrm{hp}$ yang mempunyai kecepatan putar $1800 \mathrm{rpm}$. Prototipe mesin pemotong rumput tipe rotari yang telah dirancang dan dibuat disajikan seperti tertera pada Gambar 2. 


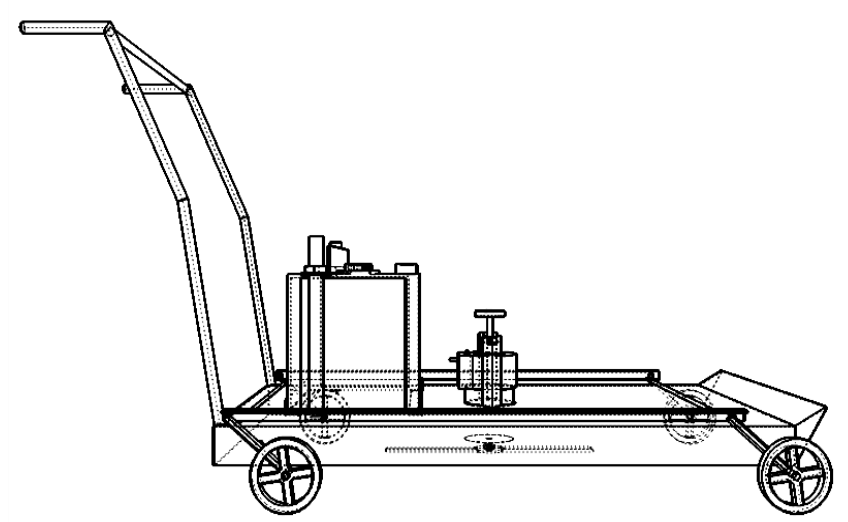

Gambar 2.Prototipe mesin pemotong rumput tipe rotari.

a) Deck

Deck dibuat dari plat besi dengan tebal $5 \mathrm{~mm}$ yang dilekukkan sehingga berbentuk lingkaran yang ditengahnya dibuat untuk dudukan untuk motor, dan dibelakang dudukan motor dibuat tempat duduka aki/baterai. Tempat lempengan pengatur ketinggian sudah berfungsi dengan baik dan sesuai dengan desain struktural.

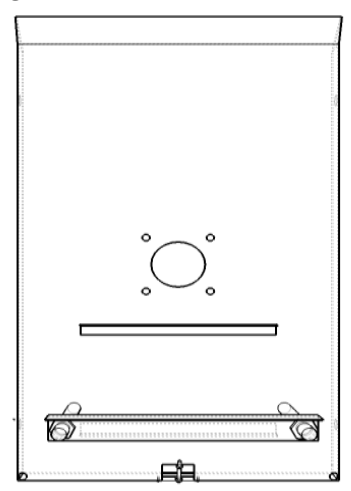

Gambar 3. Deck mesin pemotong rumput tipe rotari

b) Dudukan Motor

Dudukan motor listrik terbuat dari plat besi dengan tebal $4 \mathrm{~mm}$ yang berbentuk lingkaran dengan diameter lingkaran $15 \mathrm{~cm}$, ditengah lingkaran dilubangi berbentuk lingkaran dengan diameter lingkaran $7 \mathrm{~cm}$ sehingga poros mesin listrik akan menghadap kebawah.

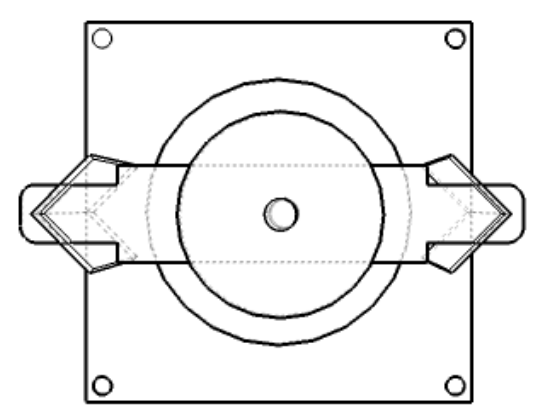

Gambar 4. Dudukan motor 
ISSN 2354-7251 (print)

c) Kemudi

Seperti terlihat pada Gambar 9, kemudi terdiri dari dua bagian yaitu kemudi bagian atas dan kemudi bagian bawah. Kemudi bagian atas terbuat dari pipa besi dengan diameter $1 / 2$ inch, dan panjang $25 \mathrm{~cm}$. Sedangkan kemudi bagian bawah terbuat dari pipa besi dengan diameter $3 / 4$ inch, panjang $70 \mathrm{~cm}$. Dengan adanya perbedaan diameter, maka pipa yang berdiameter 1/2inch dapat dimasukkan dan dikeluarkan didalam pipa yang berdiameter 3/4inc. Pada bagian kemudi terdapat saklar listrik yang berfungsi untuk mematikan dan menghidupkan mesin listrik.

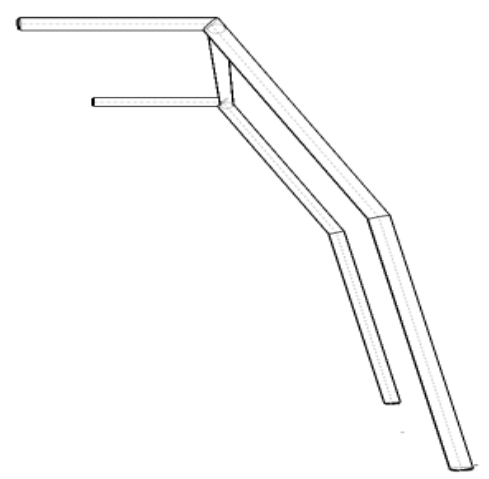

Gambar 5. Kemudi mesin pemotong rumput tipe rotari

d) Pengatur Ketinggian

Mekanisme pengatur ketinggian dengang menggunakan 4 batang sejajar. Lengan penghubung antara empat batang sejajar dihubungkan dengan baut. Batang penghubung mempunyai panjang $60 \mathrm{~cm}$ dengan tebal $3 \mathrm{~mm}$. Posisi Empat batang sejajar ada diporos roda depan dan poros roda belakang, untuk mendapatkan ketinggian deck yang sama terhadap permukaan tanah, maka Panjang dan sudut keempat batang sejajar harus sama. Dan panjang batang penghubung antara keempat batang sejajar harus sama dengan panjang antara roda belakang dengan roda depan. Dengan berputarnya tuas pengatur ketinggian potong yang disambungkan dengan poros roda, maka empat batang sejajar tersebut akan bergerak maju dan mundur sehingga deck akan terangkat naik dan turun kebawah dengan ketinggian yang sama. Plat pengatur ketinggian tersebut ditempelkan pada deck.

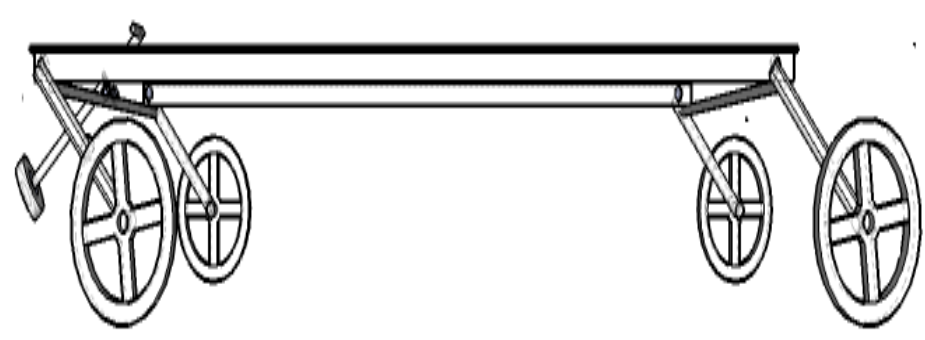

Gambar 5. Pengatur ketinggian 


\section{e) Dudukan Pisau}

Konstruksi dudukan pisau tipe potong adalah plat besi berbentuk lingkaran dengan diameter $5 \mathrm{~cm}$ yang mempunyai tebal $0.4 \mathrm{~cm}$. Pemasangan dudukan pisau dengan baut pada motor penggerak. Dengan adanya dudukan pisau yang ditekuk akan membuat sudut pemasangan pisau menjadi $20^{\circ}$ yang akan mengurangi torsi dan akan membuat kemiringan pisau menjadi $15^{\circ}$ yang akan mengurangi gesekan antara pisau dengan rumput yang telah dipotong dan akan menghembuskan hasil potongan rumput.

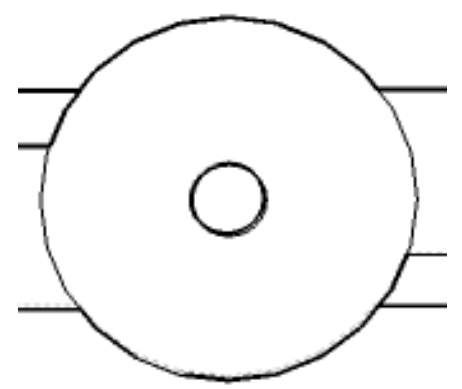

Gambar 6. Dudukan Pisau tipe dipotong

f) Pisau Pemotong Rumput

Pisau pemotong rumput merupakan salah satu bagian utama dari alat uji pemotong rumput tipe rotari yang juga penting dalam pemotongan rumput. Hal ini disebabkan proses yang berlangsung selama pengujian tergantung pada posisi pemasangan pisau pemotong. Pisau mempunyai tinggi sudut $0,5 \mathrm{~mm}$ yang akan berfungsi untuk menahan adanya defleksi akibat putaran yang tinggi untuk menghembuskan hasil potongan rumput.

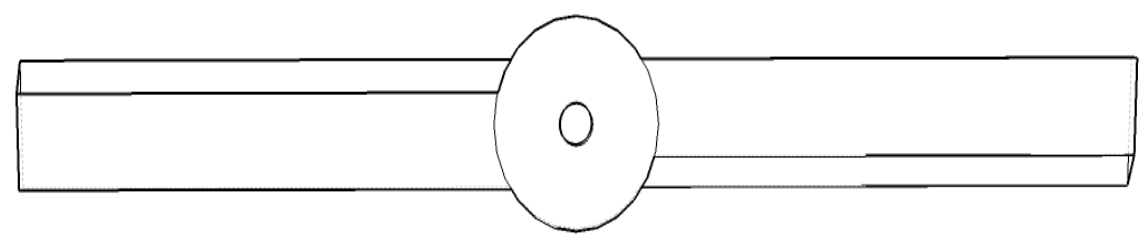

Gambar 7. Pisau Pemotong rumput

Antara mata Pisau dan dudukan pisau dihubungkan oleh baut M 12. Puli yang ada pada dudukan pisau merupakan bagian dari dudukan pisau dan bukan merupakan puli yang berfungsi sebagai transmisi putaran motor. Dudukan pisau dapat dilihat pada Gambar 11. 


\section{Hasil Pengujian}

Data hasil pengujian alat pemotong rumput tipe rotari pada lahan dengan $0,002 \mathrm{~m}^{2}$ adalah sebagai berikut:

a) Tinggi Rumput Sebelum Pemotongan

Tinggi rumput sebelum dan setelah pemotongan seperti pada Tabel 1.

Tabel 1. Data hasil pengukuran tinggi rumput sebelum dan setelah pemotongan

\begin{tabular}{llc}
\multicolumn{1}{r}{ Parameter Pengujian } & Rata-Rata(cm) \\
\hline a. & Tinggi Rumput: & 24 \\
& - Sebelum Pemotongan & 4,1 \\
& - Setelah Pemotongan & \\
\hline
\end{tabular}

Sumber, Pengolahan data primer, 2017

b) Waktu Pemotongan, Lebar Pemotongan dan Kecepatan Maju

Waktu pemotongan, lebar pemotongan dan kecepatan maju seperti pada Tabel 2.

Tabel 2. Data hasil pengukuran waktu pemotongan, lebar pemotongan dan kecepatan maju

\begin{tabular}{cc}
\hline \multicolumn{1}{c}{ Parameter Pengujian } & Rata-Rata \\
\hline b. Waktu Pemotongan, Lebar Pemotongan, dan Kecepatan Maju: & \\
- - Waktu Total Pemotongan (menit) & 9,2 \\
- Lebar Pemotongan (cm) & 32,33 \\
- Kecepatan Maju (m.s ${ }^{-1}$ ) & 0,16
\end{tabular}

Sumber, Pengolahan data primer, 2017

c) Daya Listrik yang Dibutuhkan Alat Pemotong Rumput

Daya listrik yang dibutuhkan alat pemotong rumput adalah seperti pada Tabel 3.

Tabel 3. Data hasil daya listrik yang dibutuhkan alat pemotong rumput

\begin{tabular}{llc}
\hline \multicolumn{1}{c}{ Parameter Pengujian } & Rata-Rata \\
\hline c. & Waktu Pemotongan, Lebar Pemotongan, dan Kecepatan Maju: \\
& - Waktu Total Pemotongan (menit) & 9,2 \\
& - Putaran Motor (rpm) & 1559,3 \\
& - Ketinggian Potong (cm) & 3,83 \\
& - Daya Total (Watt) & 179,67 \\
\hline
\end{tabular}

Sumber, Pengolahan data primer, 2017 


\section{Kapasitas Kerja lapang Teoritis (KLT) dan Kapasitas Kerja Lapang Efektif (KLE)}

Berdasarkan data hasil pengamatan pada pengujian alat yang dilakukan pada lahan dengan luas $20 \mathrm{~m}^{2}$ diperoleh kecepatan maju rata-rata $=0,16 \mathrm{~m} / \mathrm{s}$, lebar pemotongan ratarata $=32,33 \mathrm{~cm}$, waktu pemotongan rata-rata $=25,67$ detik, putaran motor rata-rata $=$ $1559,33 \mathrm{rpm}$, ketinggian pemotongan rata-rata $=3,83 \mathrm{~cm}$, dan waktu total pemotongan adalah $=9,2$ menit.

a) Perhitungan Kapasitas Kerja Lapang Teoritis (KLT)

$$
\mathrm{KLT}=0,36(\mathrm{~V} \times \mathrm{LP})
$$

Dimana: $\quad K L T=$ Kapasitas kerja lapang teoritis $\left(\right.$ ha.jam $\left.{ }^{-1}\right)$

$\mathrm{V} \quad=$ Kecepatan rata-rata $\left(\mathrm{m} \cdot \mathrm{s}^{-1}\right)$

Lp $\quad=$ Lebar Pemotonngan rata-rata $(\mathrm{m})$

Maka: $\quad \mathrm{KLT}=0,36 \times(0,16 \times 0,323)$

$=0,36 \times 5,17 \mathrm{~m}^{2} \cdot \mathrm{s}^{-1}$

$=0,0186$ ha. Jam $^{-1}$

Sehingga kapasitas kerja lapang teoritis alat adalah 1,86 1,86 ha.Jam ${ }^{-1}$

b) Perhitungan Kapasitas Kerja Lapang Efektif (KLE)

$$
\mathrm{KLE}=\frac{\mathrm{L}}{\mathrm{Wk}}
$$

Dimana: $\quad K L E \quad=$ Kapasitas kerja lapang efektif $\left(\right.$ ha.jam $\left.^{-1}\right)$

$\mathrm{L} \quad=$ luas lahan hasil pemotongan (ha)

Wk = Waktu kerja (jam)

Maka: $\quad \mathrm{KLE} \quad=\frac{\mathrm{L}}{\mathrm{Wk}}$

$$
\begin{aligned}
& =\frac{0.002}{0,153} \\
& =0,0131 \text { ha. } \cdot \mathrm{Jam}^{-1}
\end{aligned}
$$

Sehingga kapasitas kerja lapang teoritis alat adalah 0,013 ha.Jam ${ }^{-1}$

Kapasitas kerja lapang teoritis dan kapasitas kerja lapang efektif dapat dilihat pada tabel. 4.

Tabel 4. Kapasitas lapang teoritis dan kapasitas lapang efektif

\begin{tabular}{cc}
\multicolumn{1}{c}{ Parameter Pengujian } & Rata-Rata \\
\hline- Luas lahan (ha) & 0,002 \\
- Kapasitas Lapang Teoritis $\left(\mathrm{ha} . \mathrm{jam}^{-1}\right)$ & 0,0186 \\
- Kapasitas Lapang Efektif $\left(\mathrm{ha} . \mathrm{jam}^{-1}\right)$ & 0,0131
\end{tabular}

Sumber, Pengolahan Data Primer, 2017

Berdasarkan pengamatan, faktor-faktor yang berpengaruh terhadap kapasitas lapang efektif adalah tinggi pemotongan, tinggi rumput, kecepatan maju, dan keterampilan operator. Tinggi rumput yang besar mengakibatkan torsi pada motor penggerak akan semakin besar sehingga putaran motor kecil, begitu pula dengan 
tinggi rumput dan ketebalan rumput berpengaruh terhadap putaran dan torsi motor penggerak.

Hasil penelitian Dogherty dan Gale (1991) menunjukkan bahwa pemotongan rumput secara free cutting yang effisien mempunyai kecepatan kritis antara 25-30 $\mathrm{m} / \mathrm{s}$. pada kecepatan dibawah kecepatan kritis, defleksi batang sebelum pemotongan terjadi secarah menyeluruh sehingga energi pemotongan yang dibutuhkan tinggi. Variabel mesin pemotong rumput tipe rotari yang berpengaruh terhadap hasil pemotong adalah kecepatan putar pisau pemotong, kecepatan majunya alat, ketajaman dan jenis pisau pemotong serta sudut pemasangan pisau. Kecepatan pemotong akan berpengaruh terhadap energi spesifik pemotongan dan hasil pemotongan.

Hasil penelitian Setiadi (2000) juga menunjukkan adanya pengaruh kecepatan putar pemotongan terhadap kebutuhan tenaga pemotongan. Semakin tinggi kecepatan putar pemotongan, semakin kecil tenaga yang dibutuhkan untuk pemotongan karena torsi semakin kecil jika kecepatan pemotongan semakin tinggi. Disamping kecepatan pemotongan, jenis dan ketajaman pisau juga berpengaruh pada pemotongan. Energy spesifik pemotongan yang dibutuhkan pisau tumpul dua kali besar jika dibandingkan pisau tajam, serta hasil pemotongan lebih kasar (Dogherty dan Gale, 1991).

\section{Efisiensi Kerja Lapang (Eff)}

Efisiensi lapang dapat dihitung dengan persamaan berikut:

$$
\text { Efisiensi }=\frac{K L E}{K L T} \times 100 \%
$$

Dimana: $\quad \mathrm{KLE} \quad=$ Kapasitas kerja lapang efektif $\left(\right.$ ha.jam ${ }^{-1}$ )

$\mathrm{KLT}=$ Kapasitas kerja lapang teoritis $\left(\right.$ ha.jam ${ }^{-1}$ )

Maka: $\quad$ Eff $\quad=\frac{\text { KLE }}{\text { KLT }} \times 100 \%$

$$
\begin{aligned}
& =\frac{0,0131}{0,0186} \times 100 \% \\
& =0,704 \times 100 \% \\
& =70,4 \%
\end{aligned}
$$

Sehingga efisiensi lapang alat adalah 70,4 \%

Efisiensi kerja lapang alat didefinisikan sebagai perbandingan antara kapasitas kerja lapang efektif (KLE) dengan kapasitas kerja lapang teoritis (KLT). Berdasarkan data kapasitas kerja lapang teoritis dan kapasitas kerja lapang efektif maka diperoleh Efisiensi kerja lapang alat sebesar 70,4 \%. Berdasarkan pengamatan dan pengujian alat bahwa efisiensi kerja lapang alat sangat dipengaruhi oleh kapasitas kerja lapang teoritis dan kapasitas kerja lapang efektif, semakin besar kapasitas kerja lapang 
teoritis dari pada kapasitas kerja lapang efektif maka efisiensi kerja lapang alat akan semakin besar.

Berdasarkan pengamatan, faktor-faktor yang berpengaruh terhadap kapasitas lapang efektif adalah tinggi pemotongan, tinggi rumput, kecepatan maju, dan keterampilan operator. Tinggi rumput yang besar mengakibatkan torsi pada motor penggerak akan semakin besar sehingga putaran motor kecil, begitu pula dengan tinggi rumput dan ketebalan rumput berpengaruh terhadap putaran dan torsi motor penggerak.

\section{Kebutuhan Daya}

Kebutuhan daya dapat dihitung dengan menggunakan persamaan berikut:

$$
P=V \times I \quad \text { (Watt) }
$$

$$
\begin{array}{lll}
\text { Dimana: } & \mathrm{P} & =\text { Daya listrik yang dibutuhkan (Watt) } \\
& \mathrm{V} & =\text { Tegangan listrik (Volt) } \\
\text { Maka } & \mathrm{I} & =\text { Kuat arus listrik (Ampere) } \\
& \mathrm{P} & =\mathrm{V} \times \mathrm{I} \\
& \mathrm{P} & =12 \text { Volt } \times 14,97 \text { Ampere } \\
& \mathrm{P} & =179,67 \text { Watt }
\end{array}
$$

Sehingga kebutuhan Daya alat selama pengujian adalah 179,67 Watt

Daya yang dibutuhkan motor penggerak selama pemotongan dipengaruhi oleh waktu pemotongan. Berdasarkan data di atas dapat dilihat bahwa lahan yang luas membutuhkan waktu pemotongan yang lama sehingga daya yang dibutuhkan juga besar. Konsumsi daya pada motor selain dipengaruhi oleh waktu juga dipengaruhi oleh kerapatan dan tinggi pemotongan. Berdasarkan pengamatan kerapatan rumput pada lahan lebih besar.

Hasil penelitian Wirawan et., al 2008, menyatakan bahwa daya maksimum dan minimum untuk memangkas rumput pada keseluruhan ketinggian pangkas dengan menggunakan mesin potrum SRT-03 adalah 196,4 watt. Daya rata-rata yang dibutuhkan untuk menjalankan apparatus uji pemangkasan rumput adalah 415 watt.

Dengan menggunakan mesin pemotong rumput tipe rotari, Daya total yang dibutuhkan selama pemotongan rumput yaitu sebesar 179,67 Watt. Berdasarkan daya dari kedua mesin potong rumput tersebut, mesin pemotong rumput tipe rotari lebih efektif disbanding dengan mesin potrum SRT-03. 


\section{Kesimpulan}

Berdasarkan desain, pengamatan hasil pengujian alat dan pengolahan data: Kapasitas kerja lapang teoritis mesin pemotong rumput tipe rotary sebesar $=0,0186$ ha/jam.Kapasitas kerja lapang efektif rata-rata mesin pemotong rumput tipe rotary sebesar $=0,0131 \mathrm{ha} / \mathrm{jam}$. Efisiensi kerja lapang rata-rata mesin pemotong rumput tipe rotary sebesar $=70,4 \%$. Daya total yang dikonsumsi motor penggerak mesin pemotong rumput tipe rotary adalah sebesar $=179,67$ Watt.

\section{Daftar Pustaka}

Anonim. (1999). Toro Operator Training. Bumi Serpong

Kumurur, A.V. (1998). Rumput Lanskap Untuk Lapangan Olahraga, Taman dan Area Parkir. Penebar Swadaya, Jakarta

O Dogherty, M. J and Gale, G.E. (1991). Laboratory studies of the effect of blade parameters and stem configuration the dynamics of cutting gras. Journal of Agriculture Engineering Research, 49.

Setiadi, N. (2000). Pengaruh Sudut pemotongan Pisau Terhadap Kebutuhan Torsi Pemotongan Rumput Tipe Rotari. Skripsi Fakultas Teknologi Pertanian Institut Pertanian Bogor, Bogor.

Suharyatun, S., I N. Suastawa dan Wawan Hermawan. (2001). Analisis Mekanisme Pemotongan pada Pisau Pemotong Rumput Tipe Rotari

Suharyatun S. (2002). Analisis Mekanisme Pemotongan Rumput dengan Pisau Pemotong Rumput Tipe Rotari. Thesis. Bogor. Institut Pertanian Bogor.

Wirawan, I. P. S. (2008). Pengaruh Ketinggian Pemangkasan dengan Mesin Potrum SRT03 Terhadap Torsi Pemangkasan Rumput Bermuda (Cynodon dactylon) Tiff Way 146. Jurnal Keteknikan Pertanian, 22 (2). 